\title{
Chitosan-supported cinchonine as an efficient organocatalyst for direct asymmetric aldol reaction in water
}

\author{
Wenshan Zhao a, Chengke Qu ${ }^{a}$, Lili Yanga, Yuanchen Cui ${ }^{b, *}$ \\ a College of Chemistry and Chemical Engineering, Henan University, Kaifeng 475004, Henan, China \\ ${ }^{\mathrm{b}}$ Key Laboratory of Ministry of Education for Special Functional Materials, Henan University, Kaifeng 475004, Henan, China
}

A R T I C L E I N F O

Article history:

Received 4 September 2014

Accepted 10 October 2014

Published 20 March 2015

Keywords:

Chitosan

Cinchonine

Supported catalyst

Direct asymmetric aldol reaction

\begin{abstract}
A B S T R A C T
Chitosan-supported succinic anhydride-cinchonine (CTS-SA-CN) was synthesized via a two-step route with succinic anhydride as the linker. The catalyst was used to promote the direct asymmetric aldol reaction between cyclohexanone and a variety of aromatic aldehydes in aqueous medium. Aldol adducts were obtained in excellent yields (up to 99\%) and good enantioselectivities (up to $96 \%$ ee). The CTS-SA-CN catalyst was successfully recycled simply by filtration after use, and was reused 5 times without any significant loss of activity.
\end{abstract}

(C) 2015, Dalian Institute of Chemical Physics, Chinese Academy of Sciences. Published by Elsevier B.V. All rights reserved.

\section{Introduction}

Among the huge variety synthetic organic reactions, asymmetric aldol reactions are effective in achieving important and straightforward routes to desired $\mathrm{C}-\mathrm{C}$ backbones, while also affording valuable optically active $\beta$-hydroxyl carbonyl compounds [1-6]. With the introduction of increasingly stringent environmental protection laws, there is significant pressure on synthetic chemists to develop highly efficient synthetic routes that exert minimal influence on the environment. The development of highly stereoselective aldol reactions is a part of this trend, and interest in this area has soared in the past few decades [7,8]. Therefore, considerable research effort has been devoted to the development of commercial biocatalysts such as proline, proline derivatives, and cinchona alkaloid [9-13]. Cinchona alkaloids, although less popular than proline or proline derivatives, have also aroused much interest as potential organocatalysts for aldol reactions [14,15]. For example, Paradowska et al. [16] reported that quinine or quinidine is able to catalyze the aldol reaction with modest yield and stereoselectivity. Liu's group [17] and Kacprzak's group [18] prepared cinchona-derived amines, and found that they mediated aldol reactions between cyclohexanone or acetol and aromatic aldehydes with high enantioselectivity.

According to previous reports [14,19], small organic molecules such as amino acids and cinchona alkaloids with important applications in the field of asymmetric catalysis are difficult to recycle and reuse, which detracts from the sustainability of the resources and the process. To overcome these deficiencies, researchers have turned to the immobilization of small organic molecules [20] with the assistance of organic synthetic polymers [21] such as polystyrene [22-25] and polyethylene glycol [26,27], as well as inorganic materials like silicone [28-30] or ionic liquids [31,32]. Thus, it is expected that the environmental advantages of biopolymers will see them recognized as viable alternative supports of small organic molecules used for asymmetric catalysis [33].

Chitosan (CTS), obtained by the deacetylation of chitin, is

*Corresponding author. Tel/Fax: +86-371-23881589; E-mail: yuanchencui@126.com

DOI: 10.1016/S1872-2067(14)60248-5 | http://www.sciencedirect.com/science/journal/18722067 | Chin. J. Catal., Vol. 36, No. 3, March 2015 
the most abundant biopolymer in nature after cellulose. This material is of special interest [34] because it can be used as an active support for polymer-supported metal catalysts [35-37], while chitosan hydrogel and aerogel can be used as green and recyclable catalysts for aldol or knoevenagel reactions [38,39]. However, less work is currently devoted to the preparing chitosan-supported organocatalysts and evaluating the performance for asymmetric aldol reactions in water (an environmentally friendly solvent) than in organic solvents. In our current work, chitosan-supported cinchonine (CN) was prepared with succinic anhydride (SA) as the linker, and its catalytic performance in asymmetric aldol reactions between cyclohexanone and various aromatic aldehydes in water was investigated. Our main focus was on providing an efficient, recyclable, operationally simple, and environmentally friendly catalyst for the aldol protocol.

\section{Experimental}

\subsection{General procedures and instruments}

Commercial grade reagents and solvents were used as received except when specific purification procedures were recommended. Thin layer chromatography (TLC) was conducted on GF254 silica gel plates. Infrared spectra were recorded with an Avatar 360 Fourier transform infrared spectrometer (FTIR; Nicolet). Nuclear magnetic resonance (NMR) spectra were recorded on a Bruker Avance $400 \mathrm{M}$ spectrometer (Bruker), and the chemical shifts of ${ }^{1} \mathrm{H}$ NMR spectra were reported in relation to tetramethylsilane $(\delta=0)$. Analytical high-performance liquid chromatography (HPLC) was performed on an Agilent 1100 system (Agilent) equipped with a diode array ultraviolet detector. Separation was achieved using a Chiralpak AD column (Daicel).

\subsection{Synthesis of succinic anhydride-cinchonine (SA-CN)}

Cinchonine (1.2 g) and dichloromethane (10 mL) were added to a $50 \mathrm{~mL}$ round-bottomed flask with stirring. Succinic anhydride (0.8 g) was dissolved in $25 \mathrm{~mL}$ of dichloromethane and the solution was added dropwise into the reaction flask with 4-dimethylaminopyridine (DMAP, $0.0244 \mathrm{~g}$ ) as the catalyst. The reaction mixture was magnetically stirred at $50{ }^{\circ} \mathrm{C}$ for 5-6 h. Upon completion, the solvent was removed in vacuo to leave the crude target product as a light yellow solid. The crude product was dissolved in $25 \mathrm{~mL}$ of water and the solution was heated at $95{ }^{\circ} \mathrm{C}$ for $5-10 \mathrm{~min}$ in a water bath, followed by cooling to room temperature, and extraction with chloroform $(3 \times$ $20 \mathrm{~mL}$ ). The organic fractions were combined, dried over anhydrous $\mathrm{Na}_{2} \mathrm{SO}_{4}$, and filtered before the solvent was evaporated to give $1.32 \mathrm{~g}$ of white solid product (final purified target product) in $84 \%$ yield. The purified product was directly used for structural characterization and evaluation of catalytic performance. FTIR: 3439, 3072, 2938, 2878, 1744, 1637, 1593, 1571, $1510,1459,1384,1239,1204,1151,993,924,840,805,764$, $638,470 \mathrm{~cm}^{-1}$. ${ }^{1} \mathrm{H}$ NMR (400 MHz, $\left.\mathrm{CDCl}_{3}\right) \delta=8.85(\mathrm{~d}, J=4.4 \mathrm{~Hz}$, $\mathrm{H}), 8.22(\mathrm{~d}, J=8.4 \mathrm{~Hz}, \mathrm{H}), 8.05-8.01(\mathrm{~m}, 1 \mathrm{H}), 7.67-7.62(\mathrm{~m}, 1 \mathrm{H})$,
7.56-7.52 (m, 1H), 7.38 (d, $J=4.4 \mathrm{~Hz}, 1 \mathrm{H}), 6.83$ (d, $J=2.8 \mathrm{~Hz}$, 1H), 6.09-5.99 (m, 1H), 5.24-5.18 (m, 2H), 3.38-3.28 (m, 1H), $3.17(\mathrm{~m}, 2 \mathrm{H}), 2.81(\mathrm{~m}, 2 \mathrm{H}), 2.73-2.59(\mathrm{~m}, 3 \mathrm{H}), 2.41(\mathrm{~m}, 1 \mathrm{H})$, $2.18(\mathrm{~m}, 1 \mathrm{H}), 1.89(\mathrm{~m}, 1 \mathrm{H}), 1.72-1.53(\mathrm{~m}, 3 \mathrm{H}), 1.24(\mathrm{~m}, 1 \mathrm{H})$. Mass spectrometry (MS) (ESI, $m / z$ ): $\mathrm{C}_{23} \mathrm{H}_{26} \mathrm{~N}_{2} \mathrm{O}_{4}$ [M-H]- calculated 393.19, found 392.9.

\subsection{Preparation of CTS-SA-CN catalyst}

Dicyclohexylcarbodiimide (DCC, dehydrating agent, $0.82 \mathrm{~g}$ ), SA-CN (1.32 g), CTS (0.6 g), and dichloromethane (15 mL) were added to a $50 \mathrm{~mL}$ round-bottomed flask in the presence of a small amount of triethylamine as the catalyst. The mixture was stirred at $40{ }^{\circ} \mathrm{C}$ for $48 \mathrm{~h}$. Upon completion of the reaction, the mixture was filtered, and the residue was sequentially washed with dimethylformamide, dichloromethane, and ethanol. The residue was dried under vacuum to give the target product CTS-SA-CN $(0.76 \mathrm{~g})$ as a light yellow solid.

\subsection{General procedure for direct aldol reaction}

Substituted benzaldehyde $(0.2 \mathrm{mmol})$ was added to a reaction solution that contained cyclohexanone, a known amount of catalyst, and water or alternative solvent. The reaction was allowed to proceed at room temperature with stirring for a set duration while the reaction system was monitored by TLC. Upon completion of the reaction, the mixture was filtered and the filtrate was extracted with ethyl acetate. The organic fractions were combined, dried over anhydrous $\mathrm{Na}_{2} \mathrm{SO}_{4}$, filtered, and the solvent removed. The concentrate was purified by TLC on silica gel (ethyl acetate/petroleum ether eluent) to give pure aldol adducts. Characterization of aldol products was performed according to published procedures [40].

\subsection{Recyclability of CTS-SA-CN catalyst}

After the aldol reaction between 4-nitrobenzaldehyde and cyclohexanone, the CTS-SA-CN catalyst was collected by vacuum filtration. The filtered CTS-SA-CN catalyst was washed with ethanol and dichloromethane, and then oven-dried for $24 \mathrm{~h}$ to be ready for reuse without further purification.

\section{Results and discussion}

Scheme 1 shows the two-step route to synthesize the chiral CTS-SA-CN organocatalyst. Briefly, SA-CN is synthesized in the first step using DMAP as catalyst. SA-CN is then allowed to react with CTS and DCC in dichloromethane as the second step to obtain chiral CTS-SA-CN catalyst, which was confirmed by FTIR spectroscopy. Figure 1 shows the FTIR spectra for chitosan and CTS-SA-CN catalyst. In the spectrum of the catalyst, the broad band at around $3448 \mathrm{~cm}^{-1}$ was attributed to hydroxyl stretching, while the sharper absorption at $3328 \mathrm{~cm}^{-1}$ was assigned to the amide. The absorptions at 2928 and $2851 \mathrm{~cm}^{-1}$ were ascribed to aliphatic stretching of the $\mathrm{CH}_{2}$ in the SA-CN. The enhanced absorption at 1627 and $1575 \mathrm{~cm}^{-1}$ were assigned to the amide $\left(v_{\mathrm{N}-\mathrm{H}}\right)$ and amino groups, while the peak at $642 \mathrm{~cm}^{-1}$ was 

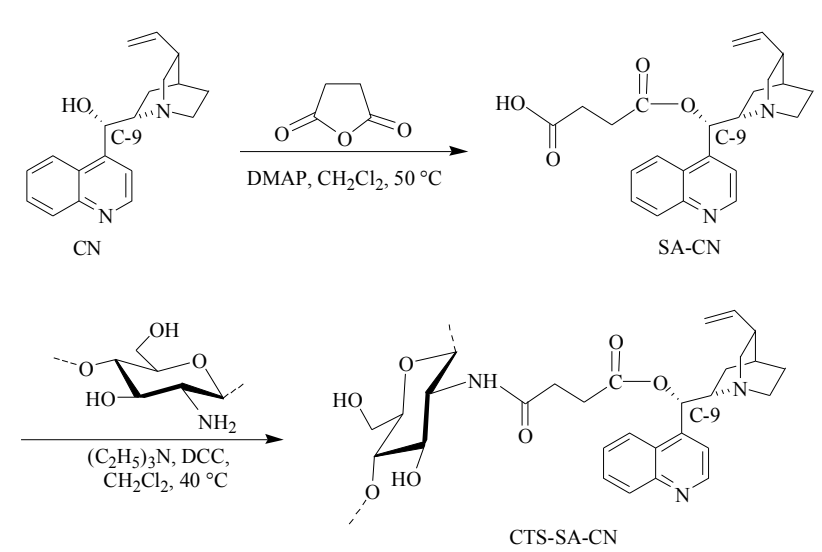

Scheme 1. General synthetic route for organocatalyst CTS-SA-CN.

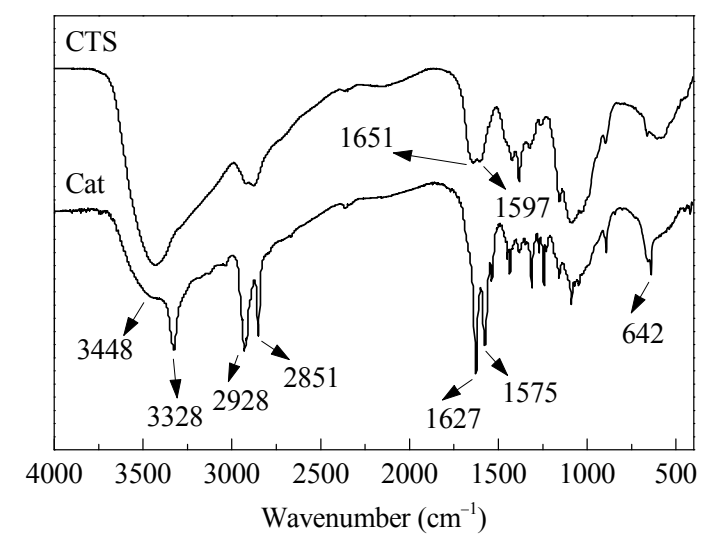

Fig. 1. FTIR spectra of chitosan (CTS) and CTS-SA-CN (Cat).

assigned to the aromatic nucleus of cinchonine.

The direct asymmetric aldol reaction of 4-nitrobenzaldehyde and cyclohexanone was selected as a model reaction to optimize the reaction conditions (solvent, ratio of substrates, catalyst loading, temperature) with CTS-SA-CN as catalyst. The performance was evaluated using different solvents and without solvent, and the results are shown in Table 1. The catalytic activity and stereoselectivity of CTS-SA-CN are highly dependent on the reaction medium. For example, the aldol adducts can be obtained with a yield of $>99 \%$ and an enantiomeric excess (ee) of $85 \%$ (Table 1, entry 6 ) in water, but the enantioselectivity depends greatly on the volume of water. When the volume of water as the reaction medium was reduced from 1.0 to 0.2 $\mathrm{mL}$, the selectivity rose from $85 \%$ to $96 \%$ ee, and the diastereoselectivity also rose therewith (Table 1, entries 6-8). The model reaction was also conducted at $0{ }^{\circ} \mathrm{C}$ in an effort to achieve higher selectivity, but no improvement was observed. In tests of catalyst type, we replaced $5 \mathrm{~mol} \%$ CTS-SA-CN with 5 $\mathrm{mol} \% \mathrm{CN}, 5 \mathrm{~mol} \% \mathrm{SA}-\mathrm{CN}$, or $5 \mathrm{~mol} \%$ CTS and found that the reaction was accelerated, but the selectivity was significantly reduced (Table 1, entries 10-12). We speculate that the primary amine of CTS and the supported CN may catalyze the reaction together leading to a significantly improved catalytic effect.

The effects of the amounts of catalyst and cyclohexanone on the model aldol reaction were investigated. The relevant results are listed in Table 2, which shows that the activity and selectivity of the catalyst greatly depend on the amounts of
Table 1

Screening of reaction conditions for the organocatalytic asymmetric aldol reaction of cyclohexanone and $p$-nitrobenzaldehyde catalyzed by CTS-SA-CN a.

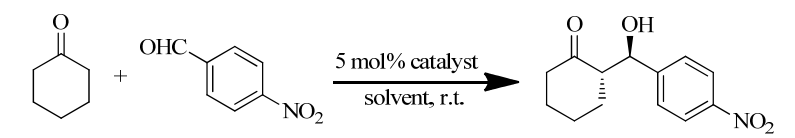

\begin{tabular}{|c|c|c|c|c|c|}
\hline Entry & Solvent & Time (h) & Yield ${ }^{\mathrm{b}}(\%)$ & $\mathrm{dr}(\operatorname{syn} / \mathrm{anti})^{\mathrm{c}}$ & ee (\%) (anti) ${ }^{c}$ \\
\hline 1 & THF & 144 & 20 & $52 / 48$ & 74 \\
\hline 2 & Hexane & 144 & 13 & $72 / 28$ & 39 \\
\hline 3 & DMF & 144 & 28 & $38 / 62$ & 24 \\
\hline 4 & $\mathrm{CH}_{3} \mathrm{CN}$ & 144 & 25 & $47 / 53$ & 64 \\
\hline 5 & Neat & 168 & 85 & $49 / 51$ & 65 \\
\hline 6 & $\mathrm{H}_{2} \mathrm{O}(1.0 \mathrm{~mL})$ & 96 & $>99$ & $33 / 67$ & 85 \\
\hline 7 & $\mathrm{H}_{2} \mathrm{O}(0.5 \mathrm{~mL})$ & 96 & $>99$ & $33 / 67$ & 88 \\
\hline 8 & $\mathrm{H}_{2} \mathrm{O}(0.2 \mathrm{~mL})$ & 96 & $>99$ & $24 / 76$ & 96 \\
\hline $9^{d}$ & $\mathrm{H}_{2} \mathrm{O}(0.2 \mathrm{~mL})$ & 168 & 56 & $30 / 70$ & 87 \\
\hline $10^{\mathrm{e}}$ & $\mathrm{H}_{2} \mathrm{O}(0.2 \mathrm{~mL})$ & 72 & 97 & $59 / 41$ & 17 \\
\hline $11^{\mathrm{f}}$ & $\mathrm{H}_{2} \mathrm{O}(0.2 \mathrm{~mL})$ & 72 & 99 & $54 / 46$ & 10 \\
\hline $12^{\mathrm{g}}$ & $\mathrm{H}_{2} \mathrm{O}(0.2 \mathrm{~mL})$ & 72 & 95 & $40 / 60$ & 75 \\
\hline
\end{tabular}

a Reaction was performed at $0.2 \mathrm{mmol}$ scale of aldehyde and 15 equivalent of cyclohexanone in the presence of $5 \mathrm{~mol} \%$ catalyst in undistilled solvent.

${ }^{\mathrm{b}}$ Isolated yield.

'Determined by chiral-phase HPLC analysis.

${ }^{\mathrm{d}}$ Reaction carried at $0{ }^{\circ} \mathrm{C}$.

e Reaction catalyzed by 5 mol\% SA-CN.

${ }^{\mathrm{f}}$ Reaction catalyzed by $5 \mathrm{~mol} \% \mathrm{CN}$.

g Reaction catalyzed by $5 \mathrm{~mol} \%$ CTS.

\section{Table 2}

Effects of the amount of catalyst and the amount of cyclohexanone on the aldol reaction between cyclohexanone and $p$-nitrobenzaldehyde catalyzed by CTS-SA-CN .

\begin{tabular}{|c|c|c|c|c|c|c|}
\hline Entry & $\begin{array}{l}\text { Catalyst } \\
\text { (mol\%) }\end{array}$ & $\begin{array}{c}\text { Cyclohexanone } \\
\text { (equivalents) }\end{array}$ & $\begin{array}{c}\text { Time } \\
(\mathrm{h})\end{array}$ & $\begin{array}{c}\text { Yield }^{\mathrm{b}} \\
(\%)\end{array}$ & $\begin{array}{c}\mathrm{dr} \\
\text { (syn/anti)c }\end{array}$ & $\begin{array}{l}\text { ee (\%) } \\
\text { (anti)c }\end{array}$ \\
\hline 1 & 2.5 & 15 & 144 & $>99$ & $32 / 68$ & 92 \\
\hline 2 & 5.0 & 15 & 72 & $>99$ & $24 / 76$ & 96 \\
\hline 3 & 7.5 & 15 & 72 & $>99$ & $37 / 63$ & 91 \\
\hline 4 & 10.0 & 15 & 48 & 91 & $40 / 60$ & 91 \\
\hline 5 & 5.0 & 5 & 144 & $>99$ & $39 / 61$ & 64 \\
\hline 6 & 5.0 & 8 & 144 & $>99$ & $38 / 62$ & 78 \\
\hline 7 & 5.0 & 20 & 72 & 99 & $33 / 67$ & 95 \\
\hline 8 & 5.0 & 30 & 72 & $>99$ & $31 / 69$ & 88 \\
\hline
\end{tabular}

a Reaction was performed at $0.2 \mathrm{mmol}$ scale of aldehyde and cyclohexanone in the presence of catalyst in $0.2 \mathrm{~mL}$ of $\mathrm{H}_{2} \mathrm{O}$.

${ }^{\mathrm{b}}$ Isolated yield.

c Determined by chiral-phase HPLC analysis.

catalyst and cyclohexanone. High selectivity (91\%-96\% ee) and high activity ( $91 \%$ to $>99 \%$ yield) were achieved in the tested range of catalyst dosage (Table 2, entries 1-4). The best catalytic performance ( $96 \%$ ee, > $99 \%$ yield) was obtained when the reaction is conducted at the optimal catalyst dosage of $5 \mathrm{~mol} \%$ in $0.2 \mathrm{~mL}$ of $\mathrm{H}_{2} \mathrm{O}$ with 15 equivalents of cyclohexanone (Table 2, entry 2). However, when the catalyst dosage was reduced to $2.5 \mathrm{~mol} \%$, a yield of $>99 \%$ and $92 \%$ ee were still obtained (Table 2, entry 1). Increasing the amount of cyclohexanone from 5 to 15 equivalents led to a significant increase 
in enantioselectivity (Table 2, entries 2, 5, and 6), but further increases in the cyclohexanone dosage over 15 equivalents caused a decrease in enantioselectivity (Table 2, entries 7 and 8 ). Accordingly, the optimized reaction conditions are suggested as $5 \mathrm{~mol} \%$ catalyst, 15 equivalents of cyclohexanone, and 0.2 $\mathrm{mL}$ of water at room temperature.

Asymmetric aldol reactions were conducted between cyclohexanone and a wide variety of arylbenzaldehydes with CTS-SA-CN as catalyst under the established optimal conditions (Table 3). The results show that aldehydes with strong electron-withdrawing substituents, such as nitrobenzaldehydes and 4-cyanobenzaldehyde, react smoothly with cyclohexanone to give excellent yields of $90 \%$ to $>99 \%$ and with good enantioselectivity of $74 \%-96 \%$ (Table 3, entries 1-5). Arylbenzaldehydes with weaker electron-withdrawing groups, like halogens, also afforded excellent yields but with slightly decreased enantioselectivity (Table 3, entries 6-8). When benzaldehyde or $p$-anisaldehyde was used as the aldol acceptor, the enantioselectivity remained moderate, but the yield decreased significantly (Table 3, entries 9,10), while no aldol condensation product was obtained when $p$-tolualdehyde was used. When cyclopentanone was used as the aldol donor, a good yield (98\%) and a moderate enantioselectivity (59\% ee) were obtained (Table 3 , entry 11), but the product mixture was roughly racemic when acetone was used as the ketone (Table 3, entry 12).

Table 4 displays the recovery and recycling test results for the CTS-SA-CN catalyst. The catalyst was recovered from the reaction of entry 1 in Table 3, and was used to catalyze the reaction between 4-nitrobenzaldehyde and cyclohexanone for an additional five cycles. The recycled CTS-SA-CN afforded good yields (from $92 \%$ to $>99 \%$ ) with slightly reduced enantioselectivity of more than $84 \%$, confirming good recovery and recy-

\section{Table 3}

Asymmetric aldol reaction between cyclohexanone and various arylbenzaldehydes catalyzed by CTS-SA-CN under optimized conditions ${ }^{\text {a. }}$.

\begin{tabular}{|c|c|c|c|c|c|}
\hline Entry & $\mathrm{R}$ & $\begin{array}{c}\text { Time } \\
(\mathrm{h})\end{array}$ & $\begin{array}{c}\text { Yield }^{\mathrm{b}} \\
(\%)\end{array}$ & $\begin{array}{c}\mathrm{dr} \\
\text { (syn/anti)c }\end{array}$ & $\begin{array}{l}\text { ee (\%) } \\
\text { (anti) }{ }^{c}\end{array}$ \\
\hline 1 & $4-\mathrm{NO}_{2}$ & 72 & $>99$ & $24 / 76$ & 96 \\
\hline 2 & $3-\mathrm{NO}_{2}$ & 72 & 99 & $32 / 68$ & 84 \\
\hline 3 & $2-\mathrm{NO}_{2}$ & 72 & 99 & $17 / 83$ & 88 \\
\hline 4 & 2,4-Dinitro & 60 & 90 & $25 / 75$ & 89 \\
\hline 5 & $4-\mathrm{CN}$ & 72 & 97 & $31 / 69$ & 74 \\
\hline 6 & $4-F$ & 96 & 99 & $26 / 74$ & 72 \\
\hline 7 & $4-\mathrm{Cl}$ & 96 & 95 & $27 / 73$ & 86 \\
\hline 8 & $4-\mathrm{Br}$ & 96 & 98 & $19 / 81$ & 80 \\
\hline 9 & $4-\mathrm{H}$ & 120 & 73 & $39 / 61$ & 67 \\
\hline 10 & $4-\mathrm{OCH}_{3}$ & 120 & 47 & $22 / 78$ & 75 \\
\hline $11^{\mathrm{d}}$ & $4-\mathrm{NO}_{2}$ & 72 & 98 & $37 / 63$ & 59 \\
\hline $12^{\mathrm{e}}$ & $4-\mathrm{NO}_{2}$ & 72 & $>99$ & - & 1 \\
\hline
\end{tabular}

${ }^{a}$ Reaction was performed at $0.2 \mathrm{mmol}$ scale of aldehyde and 15 equivalents of ketone in the presence of $5.0 \mathrm{~mol} \%$ catalyst in $0.2 \mathrm{~mL}$ of $\mathrm{H}_{2} \mathrm{O}$.

${ }^{\mathrm{b}}$ Isolated yield.

c Determined by chiral HPLC analysis.

${ }^{\mathrm{d}}$ Cyclopentanone used as ketone instead of cyclohexanone.

${ }^{\mathrm{e}}$ Acetone used as ketone instead of cyclohexanone.
Table 4

Reusability of catalyst in the aldol reaction between cyclohexanone and $p$-nitrobenzaldehyde ${ }^{a}$.

\begin{tabular}{|c|c|c|c|c|c|}
\hline \multicolumn{6}{|c|}{ 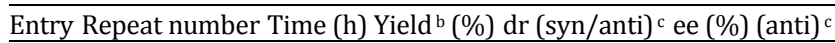 } \\
\hline 1 & 0 & & $>09$ & 24176 & cer \\
\hline 2 & 1 & 96 & 0? & 2160 & 87 \\
\hline 3 & 2 & 72 & 90 & $\begin{array}{l}51 / 07 \\
22 / 68\end{array}$ & $\begin{array}{l}81 \\
90\end{array}$ \\
\hline 4 & $\begin{array}{l}2 \\
2\end{array}$ & 96 & 96 & $\begin{array}{l}52 / 00 \\
28 / 72\end{array}$ & 86 \\
\hline 5 & 4 & 72 & $>99$ & $34 / 66$ & $\begin{array}{l}00 \\
89\end{array}$ \\
\hline 6 & 5 & 72 & 98 & $32 / 68$ & 84 \\
\hline
\end{tabular}

a Reaction was performed at $0.5 \mathrm{mmol}$ scale of aldehyde and 15 equivalents of ketone in the presence of $5.0 \mathrm{~mol} \%$ catalyst in $0.2 \mathrm{~mL}$ of $\mathrm{H}_{2} \mathrm{O}$.

${ }^{\mathrm{b}}$ Isolated yield.

'Determined by HPLC analysis.

cling capability.

\section{Conclusions}

CTS-SA-CN catalyst was prepared in a two-step route using succinic anhydride as the linker between the chitosan biopolymer and cinchonine. The performance of the catalyst in the direct asymmetric aldol reaction between cyclohexanone and a variety of substituted benzaldehydes was monitored. We found that CTS-SA-CN promoted the aldol reaction with excellent yields (up to > 99\%) and high selectivity (up to 96\% ee), even at a low dosage of $5 \mathrm{~mol} \%$ in nontoxic aqueous medium. Moreover, the catalyst can be easily recovered and reused in at least five reaction cycles with minimal loss of enantioselectivity.

\section{References}

[1] Machajewski T D, Wong C H, Lerner R A. Angew Chem Int Ed, 2000, 39: 1352

[2] Yoshikawa N, Yamada Y, Das J, Sasai H, Shibasaki M. J Am Chem Soc, 1999, 121: 4168

[3] Trost B M, Brindle C S. Chem Soc Rev, 2010, 39: 1600

[4] Markert M, Mulzer M, Schetter B, Mahrwald R. J Am Chem Soc, 2007, 129: 7258

[5] Li H H, He Y H, Yuan Y, Guan Z. Green Chem, 2011, 13: 185

[6] Zlotin S G, Kucherenko A S, Beletskaya I P. Russ Chem Rev, 2009, 78: 737

[7] Xie B H, Li W, Liu Y, Li H H, Guan Z, He Y H. Tetrahedron, 2012, 68: 3160

[8] Carrea G, Ottolina G, Lazcano A, Pironti V, Colonna S. Tetrahedron: Asymmetry, 2007, 18: 1265

[9] List B, Lerner R A, Barbas C F III.J Am Chem Soc, 2000, 122: 2395

[10] Hayashi Y, Sumiya T, Takahashi J, Gotoh H, Urushima T, Shoji M. Angew Chem Int Ed, 2006, 45: 958

[11] Gauchot V, Schmitzer A R. J Org Chem, 2012, 77: 4917

[12] Gruttadauria M, Giacalone F, Noto R. Chem Soc Rev, 2008, 37: 1666

[13] Bugde S, Majik M, Mandrekar V, Nadkarni V, Tilve S. Synth Commun, 2013, 43: 2536

[14] Huang W B, Liu Q W, Zheng L Y, Zhang S Q. Catal Lett, 2011, 141: 191

[15] Pesciaioli F, Righi P, Mazzanti A, Gianelli C, Mancinelli M, Bartoli G, Bencivenni G. Adv Synth Catal, 2011, 353: 2953 


\title{
Graphical Abstract
}

Chin. J. Catal., 2015, 36: 367-371 doi: 10.1016/S1872-2067(14)60248-5

Chitosan-supported cinchonine as an efficient organocatalyst for direct asymmetric aldol reaction in water

Wenshan Zhao, Chengke Qu, Lili Yang, Yuanchen Cui *

Henan University

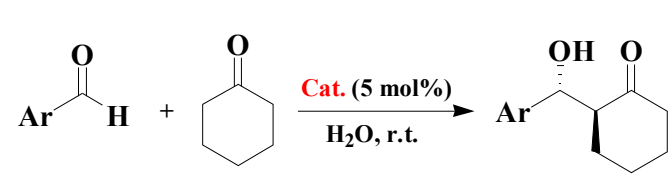

Yield up to $99 \%$, ee up to $96 \%$, syn/anti up to $24 / 76$

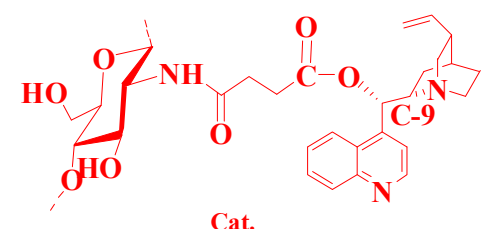

Cat.

Chitosan-supported succinic anhydride-cinchonine was conveniently synthesized. The organocatalyst catalyzed the direct asymmetric aldol reaction with excellent yields and good enantioselectivity in aqueous medium.

[16] Paradowska J, Rogozińska M, Mlynarski J. Tetrahedron Lett, 2009, 50: 1639

[17] Zheng B L, Liu Q Z, Guo C S, Wang X L, He L. Org Biomol Chem, 2007, 5: 2913

[18] Czarnecki P, Plutecka A, Gawroński J, Kacprzak K. Green Chem, 2011, 13: 1280

[19] Bisai V, Bisai A, Singh V K. Tetrahedron, 2012, 68: 4541

[20] Cozzi F. Adv Synth Catal, 2006, 348: 1367

[21] Kristensen T E, Hansen T. Eur J Org Chem, 2010: 3179

[22] Liu Y X, Sun Y N, Tan H H, Liu W, Tao J C. Tetrahedron: Asymmetry, 2007, 18: 2649

[23] Liu Y X, Sun Y N, Tan H H, Tao J C. Catal Lett, 2008, 120: 281

[24] Font D, Sayalero S, Bastero A, Jimeno C, Pericàs M A. Org Lett, 2008, 10: 337

[25] Font D, Jimeno C, Pericás M A. Org Lett, 2006, 8: 4653

[26] Benaglia M, Celentano G, Cozzi F. Adv Synth Catal, 2001, 343: 171

[27] Gu L Q, Wu Y Y, Zhang Y Z, Zhao G. J Mol Catal A, 2007, 263: 186

[28] Dhar D, Beadham I, Chandrasekaran S. Proc Indian Acad Sci Chem
Sci, 2003, 115: 365

[29] Monge-Marcet A, Cattoën X, Alonso D A, Nájera C, Man M W C, Pleixats R. Green Chem, 2012, 14: 1601

[30] Yan J C, Wang L. Chirality, 2009, 21: 413

[31] Ni B K, Headley A D. Chem Eur J, 2010, 16: 4426

[32] Kucherenko A S, Siyutkin D E, Maltsev O V, Kochetkov S V, Zlotin S G. Russ Chem Bull, 2012, 61: 1313

[33] Qin Y Y, Zhao W S, Yang L L, Zhang X, Cui Y C. Chirality, 2012, 24: 640

[34] Kumar M N V R. React Funct Polym, 2000, 46: 1

[35] Cui Y C, Zhang L, Li Y. Polym Advan Technol, 2005, 16: 633

[36] Vincent T, Guibal E. Ind Eng Chem Res, 2002, 41: 5158

[37] Viswanathan N, Meenakshi S. J Hazard Mater, 2010, 176: 459

[38] Reddy K R, Rajgopal K, Maheswari C U, Kantam M L. New J Chem, 2006, 30: 1549

[39] Ricci A, Bernardi L, Gioia C, Vierucci S, Robitzer M, Quignard F. Chem Commun, 2010, 46: 6288

[40] Qu C K, Zhao W S, Zhang L, Cui Y C. Chirality, 2014, 26: 209

\section{壳聚糖负载辛可宁催化剂的制备及其在水中催化不对称Aldol反应}

\author{
赵文善 ${ }^{\mathrm{a}}$, 曲程科 ${ }^{\mathrm{a}}$, 杨莉莉 ${ }^{\mathrm{a}}$, 崔元臣 ${ }^{\mathrm{b}, *}$

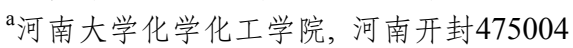

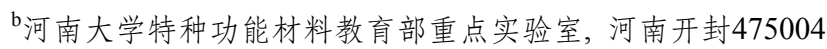

摘要: 以丁二酸䣶为连接臂, 经两步反应制备了壳聚糖负载辛可宁有机催化剂(CTS-SA-CN), 并研究了CTS-SA-CN在水体系中对 酮与多种芳香醛的直接不对称aldol反应的催化性能. 结果表明, 在CTS-SA-CN催化下, 酮与多种芳香醛发生直接不对称aldol反 应, 可得到 $99 \%$ 的产率和 $96 \%$ 的ee值. 另外, CTS-SA-CN可通过简单过滤实现回收, 重复使用5次活性并没有明显下降.

关键词: 壳聚糖; 辛可宁; 负载型催化剂; 直接不对称Aldol反应

收稿日期: 2014-09-04. 接受日期: 2014-10-10. 出版日期: 2015-03-20.

*通讯联系人. 电话/传真: (0371)23881589; 电子信箱: yuanchencui@126.com

本文的英文电子版由Elsevier出版社在ScienceDirect上出版(http://www.sciencedirect.com/science/journal/18722067). 